\title{
Discussion of Forms about Social Expenditure Cycle Driven by Human Cultural Elements
}

\author{
—Keynes Payment Framework Reconstruction during Knowledge Economy Era
}

\section{Bo Zhao, Junguang Qu}

Scientific Research Academy, Shanghai Maritime University, Shanghai, China.

Email: maimailmail@163.com, qjguang66@gmail.com

Received October $2^{\text {nd }}, 2011$; revised December $6^{\text {th }}, 2011$; accepted December $17^{\text {th }}, 2011$

\begin{abstract}
This paper reconstructed the framework of distribution of income and expenditure for the purpose of discussion of forms about social expenditure cycle driven by human cultural elements from new view. Then analyzed the relations between spiritual expenditure guided by cultural factors and the realization of commodity value, thus put forward the operation model of unbalanced growth of enterprise value by assuming behavior-driven in the humanities and social reality system: based on the value growth limitation achieved by goods social use value. And revealed its characteristic through empirical analysis: the change tendency between spiritual expenditure and its trend in income distribution, so this paper makes the conclusion that the goal of unbalanced growth of enterprise value is to stimulate the payment of social use value of commodity. This article has reference value in the requirement analysis research in this area.
\end{abstract}

Keywords: Expenditure Lead by Human Income Levels; Payment Structure; Social Use Val

\section{Introduction}

In the era of knowledge economy, various types of new industries had accumulated human wealth at the speed of non-equilibrium, and more and more enterprises had increased their quantities in the same way. What are their intrinsic reasons? Many concepts in the framework of classical economic analysis couldn't give convincing explanation. Given new issues in our society, human exploration of humanity value demand behavior had become one researching direction of economic management theory. But which couldn't reveal the nature of economic phenomena in the transformation. Because of the differences of demand of social and cultural system value, which changed both the motivation of dominating human revenue expenditure and monetary circulation structure in commodity supply and consumption. With the development of productive force, as well as the improvement of the level of social material and cultural life and the degree of education, it has reflected the purchase of goods' social use value driven by humanities values. Such purchase behaviors include the content of humanities values. Expenditure structure of products in classical economy needs to be reconstructed. There are a lot of scholars researching on the object. Such as: Keynes, three laws of psychological; Daniel Kahneman, 2002 Nobel laureate in economics, criticized this theory; scholars of knowledge economy, such as, schol- ars of the knowledge economy innovation in University of California also have researched on this object; in the article of Knowledge Management by Savage; the viewpoint of focusing on value of evaluation and value management in the theory of overall value also provided arguments for the writing of this article.

\section{Reconstruction of the Framework of Payment Allocation-Hypothesis Behavior-Driven in the Real System of Humanistic Community}

\subsection{Reconstruction of the Framework of Payment Balance-Payment Framework Driven by Cultural Element}

\subsubsection{Framework of Assumption}

1) Framework of supply and demand. At a high level of social income, supposing that there are only enterprises (the subject of social behavior) and residents (the object of social behavior). For enterprises, we called the human subject of social behavior; for residents, we called the object of social behavior with humane values.

2) Income distribution. By analyzing the expenditure approach of income, income of social agent can be divided into three parts in the distribution of consumption:

a) For the distribution of the first level of material sup- 
ply, to meet the consumption in the material living.

b) For the distribution of spiritual consumption, to meet the demand for higher levels of social agent. This part has the characteristic of social use values.

c) For savings, which is used to counterpoise the balance part in the supply and demand equilibrium framework between enterprises and residents.

3) Logic icons:

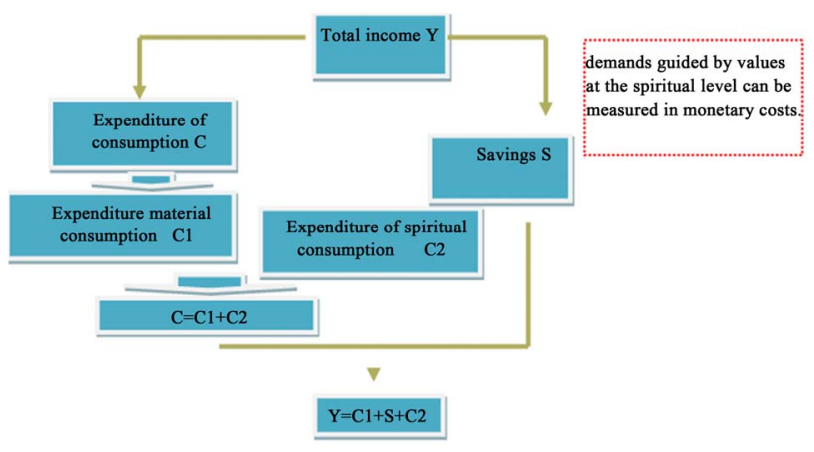

4) Formula of the equilibrium relation:

The above equilibrium structure can be divided into the following three parts of balance content.

a) $\mathrm{C}$ (for consumption, part of income),

$\mathrm{C}$ is divided into two parts: $\mathrm{C} 1$ (for material consumption); $\mathrm{C} 2$ (for spiritual consumption);

b) $\mathrm{S}$ (for savings part in your income);

c) $\mathrm{Y}$ the income of social agent;

Where, $\mathrm{C}=\mathrm{C} 1+\mathrm{C} 2$,

Formula of equilibrium relation: Income $\mathrm{Y}$ means the sum of three components: $\mathrm{Y}=\mathrm{C} 1+\mathrm{S}+\mathrm{C} 2$.

\subsubsection{Tendency of Social Agent's Payment}

For the above spending behavior of consumption and savings, we quote Keynes predilection of psychological theory to analyze the concept. We can split and use its tendency of consumption $\Delta \mathrm{C} / \Delta \mathrm{Y}$, divided into:

1) Tendency of material consumption $\Delta \mathrm{C} 1 / \Delta \mathrm{Y}$, we think material demand is decided by economic man's characteristic, it guides social agent in the field of consumption and expenditure by the market price mechanism. Tendency of material consumption means extent of reaction of expenditure of material consumption to change of income.

2) Tendency of spiritual consumption $\Delta \mathrm{C} 2 / \Delta \mathrm{Y}$, we assume that spiritual demand is decided by the sense of values. Merit included in the goods guides consumption and expenditure of social agent, tendency of spiritual consumption means extent of reaction of expenditure of spiritual consumption to change of income.

3) Tendency of savings $\Delta S / \Delta Y$, it means extent of reaction of savings to change of income.

Formula of equilibrium relation:

$$
\Delta \mathrm{C} 2 / \Delta \mathrm{Y}+\Delta \Delta \mathrm{S} / \Delta \mathrm{Y}+\Delta \mathrm{C} 1 / \Delta \mathrm{Y}=1
$$

\subsubsection{Logic Icons}

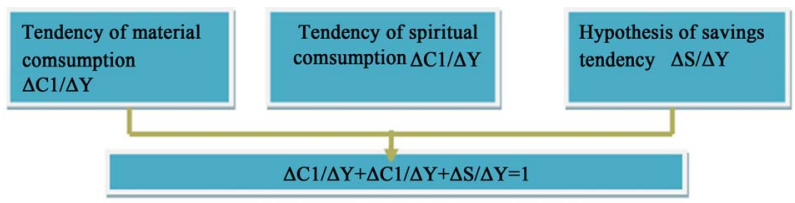

\subsubsection{The Savings Regulation Part}

1) Conditions of Kay's balance. To make the macroeconomic environment balanced, the conditions of balance should be in consideration: all income equals to expenditure and investment. In traditional economics, the savings $\mathrm{S}$ must be translated into investment $\mathrm{I}$, This is the condition of both balance of payment and clearing market, $\mathrm{S}=\mathrm{I}[1]$.

2) Spiritual demand of not all market clearing. From the view of demand, it savings equals to investment, not the prerequisite of clearing market, social agent has meet basic material needs, and has the saving part of spiritual expenditure, spiritual expenditure of social agent can't be regulated by the price mechanism of market. So, after savings is translated into investment, the supply of enterprise can be realized or not (making all resources clear), it hasn't been decided by the price mechanism of market.

Diagrammatic presentation: (according to compatible part of Market and the Value Model on above picture).

Given to the changes three balanced parts made to classical equilibrium framework, we need knowing the interior of social agent's spiritual expenditure and savings running in payment, how to realize the balance, and understand the effect on economic growth?

\subsection{The Growth of Spiritual Expenditure in Income Distribution-Groups of Different Cultural Spheres Based on Expenditure Difference Driven by Different Humanism Feature}

\subsubsection{Prerequisite of Income's Spiritual Expenditure}

The form of income's humanization expenditure is formed after meeting basic material living and having excess assets, this issue can be discussed in two stages.

1) When $Y \leq C 1$, social agent mainly reflects characteristics of economic man, income is in pursuit of economic interest after meeting basic material living. Price has an effect on the allocation of resources, then, price changes around the value, consumer buys goods in market price. This part is out of our discussion.

2) When $Y>C 1$, social agent has excess assets after meeting basic material living, the demand of humanistic value belonging to high level begins to guide the expenditure of social agent's excess income, humanistic value has the characteristics of social use value, and begins to allocate the resource allocating of the rest. Then, the sur- 
plus will translate into saving S. Keeping the balance of payment $\mathrm{Y}=\mathrm{C} 1+\mathrm{S}+\mathrm{C} 2$.

\subsubsection{The Growth of Income's Spiritual Expenditure}

1) The growth of income's humanization spiritual expenditure, we want to obtain the relationship among income $\mathrm{Y}$, consumption $\mathrm{C}$, material consumption $\mathrm{C} 1$ and spiritual $\mathrm{C} 2$, assuming that $\mathrm{C} 1$ is stationary. With the growth of $\mathrm{Y}$, the result of $(\mathrm{C} 2 / \mathrm{C})$ increases. At this time, the increasing relationship between $\mathrm{C} 1$ and $\mathrm{C} 2$ is opponent. The proportion of spiritual demand increases, but the tendency of spiritual consumption is on the increase. The expenditure searching for the satisfaction of humanization demand is of a large proportion of social agent's income gradually, and reflects the growing tendency. In this situation, that income of demand expenditure in basic material living adjusted by the market price mechanism is of extremely small proportion.

2) The growth of spiritual expenditure tendency. We think that income is stationary in some stable stage. The tendency of spiritual expenditure $\Delta \mathrm{C} 2 / \Delta \mathrm{Y}$ is stable or a constant. But with the growth of investment translated by savings $\mathrm{S}$ that income increase, and the growth of basic material consumption is slow, the change of material consumption tendency is on the small side, but the expenditure of humanistic value in the payment is Increasing, in this way, the tendency of spiritual expenditure has a trend of increasing.

3) The accelerating change of growth. With the increasing of investment, investment multiplier effect accelerates economic growth and income, the tendency of spiritual consumption shows a momentum of accelerated growth. In the distribution of income, the growth of investment translated by savings also influences the growth speed of spiritual consumption and the relationship between the change speed of spiritual consumption and the growth speed of income change, and this can also influence accelerative and reversed change law of tendency between material consumption and spiritual consumption.

4) The growth of spiritual expenditure influences. The demand of social use value.

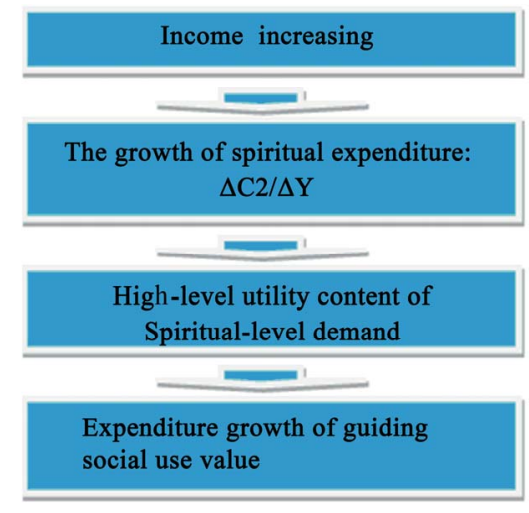

\subsection{Impact Assessment of Spiritual Expenditure Guided by Income Culture on the Realization of Goods Value}

The main factors effecting on humanization expenditure of income:

1) High level of income generates the tendency of spiritual expenditure, then the growth of economy and income influences the spiritual expenditure of income, the changes of both spiritual expenditure and the tendency of spiritual consumption is positively correlated with the growth change of economy and income.

2) Humane value influences the behavior of spiritual expenditure in income, groups of social behavior with different humane value have different tendency of spiritual expenditure.

3) In the unstable situation of society, such as war, people will take the measures of advance savings and metastatic investment to avoid disaster.

4) Because of the unsettled economic environment or to avoid inflation and fluctuations in policy, the enthusiasm to provide for the aged appears, people will take measures, such as savings, investment, portfolio investment and maintaining value, to make income disposable. At this time, the enthusiasm of seeking enjoyment of humane value drops, the behavior of spiritual expenditure in income will be influenced.

\section{The Analysis on the Relations between Spiritual Expenditure Guided by Cultural Factors and the Realization of Commodity Value-Based on the Analysis on Theory of Non-Balanced Growth of Enterprise Value}

\subsection{Equilibria Model of the Operating Expenses about Social Groups Spirit}

\subsubsection{Spirit Expenditure Behavior}

1) Spirit expenditure behavior. At a higher income level, income distribution of social agent uses not only in material consumption but also in the saving part of spiritual consumption, and the latter can provide social agent higher social use values. Analysis on payment behavior is based on enterprise creating goods' social use value.

Analysis on spiritual expenditure of social agent influences the saving part of their income. We look on analysis on spiritual expenditure behavior of social agent based on human value of production as the focal point of research on social agent's payment behavior.

2) The stage of income and expenditure. With the growth of personal income, the internality motion of human value significance driving the value behavior of social agent has been revealed gradually, and influenced the spiri- 
tual expenditure behavior of social agent, because of differences of productive forces, the motivation of leading social agent's payment is different [2]. The payment behavior of social agent can de divided into two parts, behavior of expenditure in material life guided by Economic man and spiritual expenditure behavior of social agent, the former has the characteristic of seeking to cheap commodity based on natural use value, the latter seeks the effectiveness brought by goods' social use value which has the purpose of meeting Subjective value perception. The purpose of Production of human values is to create goods social use value at the higher income level, and meets the effectiveness of social agent. In this case, payment relation of new human value productiveness will be formed.

\subsubsection{Composition of Spiritual Expenditure}

If we make humane world environment as independent variable, social agent's subjective cognitive of psychological value (cognition of social use value) as dependent variables. So we can analyze social problems like this. Enterprises shape goods' social use value by the way of copying imitating and illogically creating human values, which can support social agent to transfer the knowledge of goods' natural use values into the knowledge of its social use values, the way of enterprises getting social agent's information of value model is equal to achieving social use value. It is an important way of knowing and guiding social agent behavior of value demand in future. In this way it can predict and guide the supply and demand of social agent in future.

So we can analyze how enterprises achieve goods' social use value.

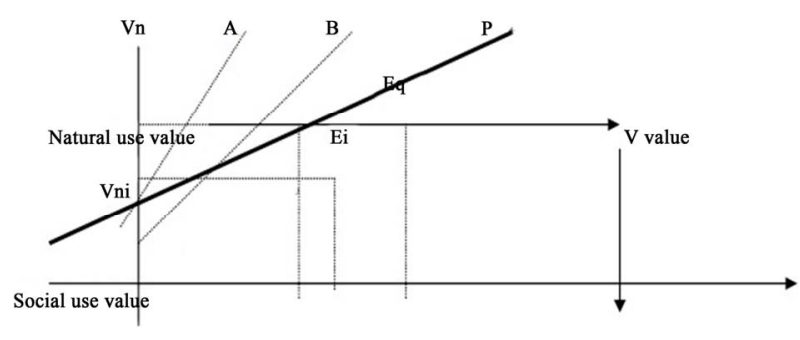

Vs

$\mathrm{Pi}$

(From J. Qian "Labor Theory of Value"),

Where: horizontal axis vs. social use value;

vertical axis: natural use value;

$P$ curve: the price curve of a certain slope;

A, B curve: the curve of social use value with different slope;

$\mathrm{Ei}(\mathrm{Pi} ; \mathrm{Vni})$ : natural use value and price of one point in the curve of social use value;

The point of Eq: limit point which social use value, natural use value and price limited by the abstraction of value.

Directions: the point of Eq notes that no matter how they are rich and perfect, any types of labor product have the regularity of attribute, and have the limitation of its labor inputs. If the limitation is exceeded, the value will more than social maximizing cognition of its attribute. Such as: social cognition of regularity of cars' attribute is the car not the space shuttle in spite of its development and perfection. So, for any of goods, its natural use value, social use value and price have the regularity of attribute. This is Eq, the maximum equilibrium.

Conversion factor guided by social use value is a, a means slope.

The relationship between natural use value and price: $\mathrm{Vn}=\mathrm{b}+\mathrm{aP}$ ( $\mathrm{b}$ means intercept, a means slope).

1) Social use value of goods focuses on and forms transformation mechanism of currency payment. There are some functional relationships among natural use value, social use value and price. So the realization of social use value is based on conversion effect on functional relationships between natural use value and price. The result shows:

The relationship between social use value and natural use value: $\mathrm{Vs}=\mathrm{a}+\mathrm{bVn}$ (a means constant, $\mathrm{b}$ means conversion factor between Vs curve and natural use value $\mathrm{Vn}$ ).

The relationship between social use value and price: $\mathrm{Vs}=-\mathrm{a}+(1 / \mathrm{b}) \mathrm{P}(\mathrm{a}$ means constant, $\mathrm{b}$ means conversion factor between Vs curve and natural use value $\mathrm{Vn}$ ).

When Evs $<$ Ep, social use value is conforms to price, then, the relationship between natural use value and above situation can reflects:

Conversion factor guided by social use value is a, a means slope [3].

The relationship between natural use value and price: $\mathrm{Vn}=\mathrm{b}+\mathrm{aP}$ (b means intercept, a means slope).

2) Appraisal: the structure of humanization expenditure of social agent's income. Significance of human values guides social agent to form subjective judgment of social use value and to adopt the behavior of actual payment. So in the social agent's expenditure of goods' social use value, it consists of two parts from the source point of view, but social use value is due to the perception of objective value, so the value composition of social use value has functional relationship with natural use value and price.

\subsection{The Analysis on Running Process of Payment Curve of Goods' Social Use Value}

\subsubsection{Marginal Utility Analysis on Goods' Social Use} Value: Principles of Formation of Value

1) Payment curve of goods' social use value. The de- 
mand curve of goods' social use value stands for the locus of social use value expenditure of social agent's income. Because social agent would like to pay for social use value which can bring social agent significance of human values with high income. Social agent paying quantity of money for social use value standing for utility satisfaction gotten from social use value.

2) Diminishing marginal utility of goods' social use value. From the source of social agent getting utility satisfaction, it is composed by material product and humane value, because the utility brought from the consumption process to consumption agent is diminishing marginal with the increase in consumption. So MV curve is diminishing marginal. Because interference variables brought by significance of humane value is a constant ( $a, b$ constant), so MUs curve is diminishing marginal.

3) The location of payment curve of goods' social use value. In the humane value activities of enterprises, enterprises must create goods' social use value which is more than its natural use value. Only in this way its behavior is meaningful. MVs curve after being translated by certain interference variables will be above MV curve.

\subsubsection{The Change Law of Demand Curve of Social Use Value: The Basic Form of Change}

According to subjective theory of value and marginal utility [4], the demand curve of material goods is derived from the law of diminishing returns, according to the law of diminishing returns of material goods consumption in the following chart, we can get the corresponding demand curve DD, and we can get the demand curve of social use value DsDs according to the law of diminishing returns of social use value, both of them all reflect the tendency of gradually decreasing from top-left to bottom-right. We can draw the conclusion that the price of goods' material serviceability reduces gradually. But the utility satisfaction brought from goods social use value to social agent is also depressed gradually. DsDs curve locates the top right of the curve DD. perpendicular to the abscissa, DsDs curve is Vertical than the height from P1 to P0 in DD curve.

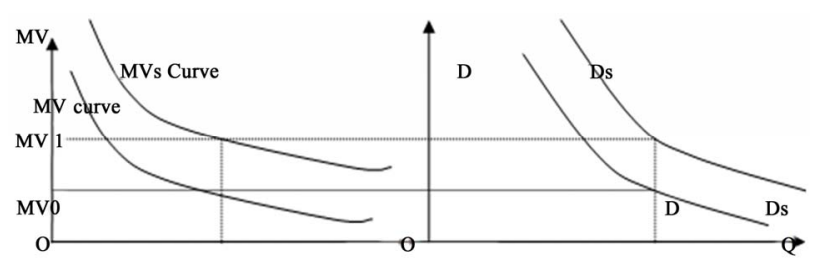

Where: MV curve: marginal utility curve of material goods consumption;

MVs curve: marginal utility curve of social use value;

DD curve: the demand curve of goods;

DsDs curve: the demand curve of social use value.

\section{Operation Model of Unbalanced Growth of Enterprise Value: Based on the Value Growth Limitation Achieved by Goods Social Use Value}

\subsection{The Acknowledge of Maximizing Social Use Value and Currency Payment Factor of Goods}

\subsubsection{The Concept of the Acknowledge of Maximizing Social Use Value}

The acknowledge of maximizing social use value, short for MVS (Maximum Value Sense, from MVP, MVS is a new concept), is the subjective maximum utility satisfaction social agent has on social use value of goods. Enterprise integrates the content of humane value into goods or service by the way of copying, imitating and creating logically model of humane value, the purpose is to make social agent get the greatest degree of satisfaction and enjoyment from goods and servicing social use value. The approval based on subjective value judgments from social agent and having effect on goods social use value is maximum acknowledge of humane value. Which are business activities of human values purpose, and is the premise of enterprise getting the largest loyalty from social agent.

\subsubsection{The Ultimate Value of the Acknowledge of Social Use Value}

1) Level constrained line. Theory of subjective utility has an analysis on goods' consumption based on goods natural use value, according to Imputed theory "the consumer has the maximum utility satisfaction when he is purchasing the first unit of commodity" [5]. This recognition is reasonable, it can also have application in the analysis on the content of goods' human value. We call the value consumers get when they are purchasing the first unit of commodity the social agent maximum or limitation payment for humane value. This is level constrained line. But except for tangible goods or intangible goods for aesthetic enjoyment, such as crafts, treasures and artworks, because spirit commodity has no natural use value, even it has the material carrier which isn't the carrier of value. So, the foundation of the acknowledge of spiritual value is not the natural use value of material commodity, it is the social use value of spirit enjoyment, the value of spirit commodity builds on spiritual values based on cultural aesthetics of thousand of history.

2) The reasoning of inverse method. Assuming that the purpose of the community of goods is to use its natural use value, with the growth of consumption, if enterprises create the social use value of goods and service by the participation of the content of humane value, then, when social agent purchases the commodity or service, will his payment exceed the payment of purchasing natural use 
value of the first commodity? We don't think so. To fulfill the first level of basic material needs of life, the utility satisfaction of costumer purchasing the first commodity is maximal, and the payment is maximal, even though blending the content of humane value into goods, the payment of the commodity or service will not beyond the limitation. Just as consumers won't look on a TV as a space ship.

3) The oppression of essential attribute of goods. Because social use value of goods is in control of essential attribute of goods, the expenditure of social agent will not beyond the range of essential attribute of goods, just as you can't buy a TV in the price of space ship. Any commodity and service is based on providing natural use value, playing a role with the law of diminishing marginal utility, how to make social agent get greater utility? Enterprises blend humane value into goods and service to create social use value in the purpose of guiding consumers to pay. Only in this way, social agent will have higher level of enjoyment and satisfaction, and improves degree of their subjective utility. Enterprises will win the competition. After all, payment for goods and service is based on consuming natural use value. The payment for the maximal limitation of basic material needs restrict the maximum value of the payment for natural use value. If the price of goods and service exceed the limitation, social agent will choose the goods of appreciate price, because his purpose is to use its natural use value, based on above, the goods and service including the content of humane social value will break away from mental constraints of consumption of natural use value once that exceeding the limit price.

Besides, if the purpose of social agent is to get spiritual satisfaction, and he will focus on the consumption of humane goods and service. Different humane goods and service has different cognized value for social agent. Utility satisfaction that humane goods and service with stable value content having of social agent obeys the law of diminishing returns, with the increase of content of humane values, value content of humanism included in humane goods can be cumulative.

\subsection{The Change of the Location of Payment Curve of Social Use Value and the Process of the Growth of Enterprise Value}

\subsubsection{Assume}

1) Ordinate axis $V$ stands for the utility satisfaction of social agent consuming some goods, cross shaft $\mathrm{Q}$ stands for the quantity of social agent consuming some goods.

2) MV1 means that utility satisfaction social agent gets is degressive with the growth of the consumption quantity of goods.

3) Level constrained line of $\mathrm{ABCE}$ is the maximum acknowledge of humane value social agent gets, and stands for the limitation MVS humane value pays.
4) To satisfy the need of social agent, the commodity will keep creating and adding new social use value created by the content of humane value to attract social agent. MVi stands for marginal utility curve of goods' social use value adding new humane value.

5) Different curve of MVi is suppressed by level constrained line, making the maximum possibility that social use value of goods adding new humane value brings social behavior locates in the point of A, B, C $\cdots \mathrm{E}$.

\subsubsection{Illustration}

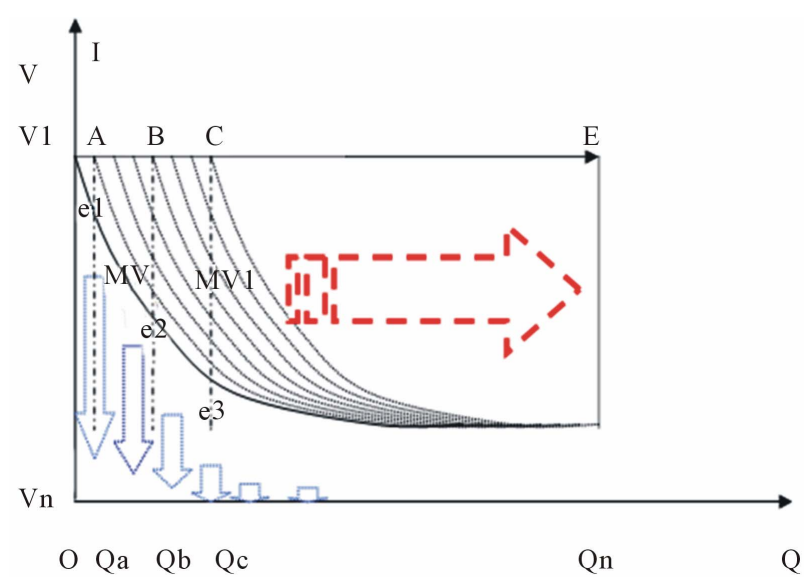

\subsubsection{Explanation}

Enterprise updates humanistic values in different period, providing to create new social use value of goods, MVi curve will get a new and higher starting point, if the product supply can be fractionized, the maximum payment of social agent locates in V1 (ABCE) of the line, MVS, such as on the point of $\mathrm{Qa}$, blending the content of humane value into product, then the apogee of the payment of social agent guided locates in A point, namely: $\mathrm{AQa}=\mathrm{U} 1$. This is the apogee limitation of the payment of social agent, which can achieve the utility in the area of P1OQnA.

V1E means the level constrained line, the satisfaction social agent gets is peak when social agent is consuming the natural use value of the goods for the first time, this is the limitation of value of the judgment when consumption agent who is increasing with the growth of consumption quantity gets the maximum utility of the social use value of the goods, with the consumption social agent is in of goods, the utility social agent gets in the second, third consumer falls off. But, if the enterprise keeps innovation and increases the value content of humane value of goods, which can gain the satisfaction. The ultimate value social agent would like to pay is equal to the maximum payment when social agent buys the goods for the first time when the increasing of the utility social agent gets influences the increasing of his payment, locates on the line of V1E, the ultimate value of maximum of profit enterprises chase by the way of innovation also locates in the same 
level of V1E.

\subsection{Target of Unbalanced Growth of the Enterprise: Stimulating Payment of Social Use Value of Goods}

The maximum acknowledge of humane value created is the maximum of social use value enterprise creates in essence, the thorough understanding of the maximum content of humane value acknowledge created is necessary very much.

\subsubsection{What Is the Humane Value of Enterprise Searching?}

Peter F Druke, in 1997, thought that "the maximum of consumer satisfaction is the foundation of the maximum of enterprise value" what the humane value of enterprise searches is the maximum utility satisfaction enterprise gets from the social agent use of goods, for the purpose of improving consumer satisfaction, which can make enterprise value maximal [6]. The value content enterprise improves of the social acknowledge of goods exists in the humane society social agent takes part in, it need enterprise explore and analysis, only in this way, what the social agent want can be found the process sought is the activities and behavior of humane value.

The activities of humane value must connect with the utility and satisfaction social agent can get, they are inadvisable without any of each other.

\subsubsection{Providing the Satisfaction of Goods' Social Use Value}

The utility satisfaction which can bring social agent the significance of humane value. Payment for social use value guided by humanity means a merit for social agent. But for enterprise, making social agent experience fulfilling in accordance with the social realization of goods or service, it means final - the arrival of purpose value achieves [7].

\subsubsection{The Acknowledge of Achieving the Maximum of Social Use Value}

It means that social agent identifies with the superlative form of goods' value. What the enterprise want to search is to search and fulfill the demand of the superlative form of value significance from social agent. The degree of cog- nition is the acknowledge of the essence of goods and service.

The maximum utility fulfilling is based on the maximum acknowledge of goods and service. Enterprise searches the access to fulfilling the highest level of demand of social agent by making goods and service significance of humane value, which can create a precondition of making social agent's income maximum. Successful enterprise creates new value of product and service in this way, striding forward maximum they called.

\section{Empirical Analysis: The Change Tendency between Spiritual Expenditure and Its Trend in Income Distribution}

We evaluate statistical data to the distribution of payment of 500 random social agents, to get the information of the change tendency between spiritual expenditure and its trend in income distribution.

\subsection{The Distribution Part of Spiritual Expenditure of Income Provides the Analysis on the Payment of Social Use Value}

\subsubsection{Purpose of the Survey}

To define the proportion of spiritual expenditure of income, to define whether social use value evaluated by sense of worth has the ability of currency payment.

\subsubsection{The Design of Survey}

Including three variables: Income Change、spiritual expenditure change and basic living expenditure change, to describe the changes of spiritual expenditure and basic living expenditure with income.

\subsubsection{Evaluation Criterion}

If the difference between spiritual expenditure and basic living expenditure in the payment behavior of social agent increases with the growth proportion of income, then the spiritual pursuit of social agent has the condition of currency payment in income, the more spiritual expenditure is, the stronger the effect sense of worth has an on the expenditure behavior of social agent is.

The change of income distribution effected by income change (see following chart).

\begin{tabular}{ccccccccccccc}
\hline Income change (yuan/year) & 2000 & 4000 & 6000 & 8000 & 10,000 & 12,000 & 14,000 & 16,000 & 18,000 & 20,000 & 22,000 \\
\hline Income change (yuan/year) & 800 & 1700 & 2750 & 3800 & 4900 & 6050 & 7270 & 9170 & 11,070 & 12,970 & 13,920 \\
& 24,000 & 26,000 & 28,000 & 30,000 & 32,000 & 34,000 & 36,000 & 38,000 & 40,000 & 42,000 & 44,000 \\
Income change (yuan/year) & 15,590 & 17,070 & 19,070 & 21,070 & 23,070 & 25,070 & 27,470 & 29,970 & 32,570 & 35,270 & 38,170 \\
The change of spiritual expenditure (yuan/year) & & & & & & & & & & & &
\end{tabular}


Analysis: with the change of income, the proportion of the expenditure of basic living is increasing gently, but the rate of change of spiritual expenditure is increasing greatly. And spiritual expenditure has an unconditional proportion in the distribution of income.

Conclusion: because social agent is guided by the sense of worth in the distribution of income, so, the social use value created by social agent in the value activity gets the prerequisite of currency payment. And spiritual expenditure has an unconditional proportion, conclusion that cultural values has a control effect on the payment behavior of social agent, this is the precondition of the payment carried on by social agent enterprise arouses in the dynamic behavior.

\subsection{The Tendency of the Change of Spiritual Expenditure Caused by the Income Change}

We have dealt with the above statistics, and get the tendency chart of the change of spiritual expenditure caused by income change.

\subsubsection{Hypothesis}

1) Horizontal axis: stands for the growth of income;

2) Ordinate axis: stands for the growth of spiritual expenditure;

3) Purpose: analysis on the change of spiritual expenditure with the change of income.

\subsubsection{Evaluation Criterion}

1) If the spiritual expenditure accelerates its growth with the increasing of income, to illustrate that the expendi- ture behavior of social agent is out of control of the price mechanism, the priming action of sense of worth having effect on the spiritual expenditure of social agent is stronger more and more. Cultural values have a control effect on consumer's payment behavior.

2) The phenomenon of the price mechanism failure is stronger more and more, the problem that market not clearing resources in classical framework is obvious more and more, the theory of equilibrium of supply and demand guided by price has a mistake in analysis on enterprise value.

The tendency of the change of spiritual expenditure caused by income change.

Analysis: statistical analysis of sampling data, from the chart, the change of payment is accelerative with the increasing of income.

Conclusion: in the payment behavior of social agent, the psychological value aroused by human sense of worth plays a regulatory role in the behavior of spiritual expenditure with the growth of income.

\subsection{The Change Tendency of Spiritual Expenditure with the Change of Income}

\subsubsection{Statistical Summary on the Tendency of Spiritual Consumption}

We make a statistical summary on above sample data, we get the data of payment tendency in different situation of income change after calculation.

Statistical summary on the tendency of spiritual consumption:

\begin{tabular}{|c|c|c|c|c|c|c|c|c|c|c|}
\hline Income change (yuan/year) & 2000 & 4000 & 6000 & 8000 & 10,000 & 12,000 & 14,000 & 16,000 & 18,000 & 20,000 \\
\hline Tendency of spiritual consumption & 0.4 & 0.425 & 0.4583 & 0.475 & 0.49 & 0.504 & 0.519 & 0.573 & 0.615 & 0.6485 \\
\hline Income change (yuan/year) & 24,000 & 26,000 & 28,000 & 30,000 & 32,000 & 34,000 & 36,000 & 38,000 & 40,000 & 42,000 \\
\hline Tendency of spiritual consumption & 0.65 & 0.656 & 0.68 & 0.7 & 0.72 & 0.737 & 0.763 & 0.789 & 0.814 & 0.8398 \\
\hline
\end{tabular}

\subsubsection{Trend Curve of the Tendency of Spiritual Consumption}

1) Horizontal axis: stands for the change disagree of income: $\triangle \mathrm{Y}$;

2) Ordinate axis: stands for the tendency of spiritual expenditure: $\triangle \mathrm{C} 2 / \triangle \mathrm{Y}$;

3) Curve: stands for the change tendency of the tendency of spiritual expenditure with the increasing of income.

The change tendency of tendency of spiritual expen- diture with the increasing of income:

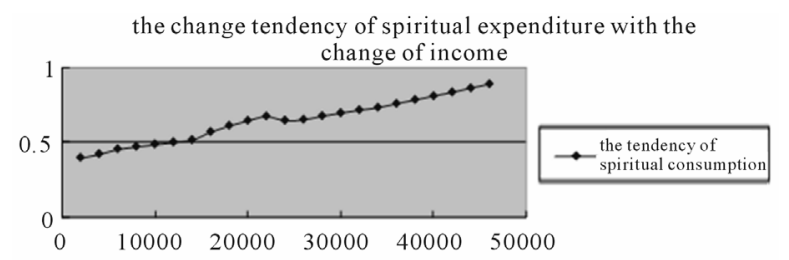

Conclusion: the expenditure of spiritual consumption $\mathrm{C} 2$ and the tendency of spiritual consumption will be in- 
creasing gradually, and the tendency of spiritual consumption will increases at higher speed, the more the speed of income change is, the increasing speed of the tendency of spiritual consumption will be.

Annual income in 30,000 yuan (on 20,000 yuan point of the horizontal axis, the expenditure of basic living is 10,000 yuan, total income is 30,000 yuan) is a stage, this stage locates at the peak of a stage with income increase. After the adjustment in last period, the tendency of spiritual expenditure is increasing in accelerative way. Conclusion that the quality of basic living begins to increase the quality demand when monthly income reaches 3000 yuan. Then, in the condition that expenditure of basic living has a smaller elastic constraint, the tendency of spiritual expenditure keeps increase in the accelerative way.

\subsection{The Significance of Analysis on the Payment Behavior}

\subsubsection{The Significance of the Growth of Enterprise Value}

Given the high income of social agent, the expenditure of basic living has a small proportion of income, the more payment is guided by the significance of humane value. Social use value formed by social agent guiding the value significance takes the cognitive style of subjective value to determine the value, and is based on abstract value. So, the market can't adjust the income of special value dominated by social agent based on pursuing non-economic benefits. The analysis framework of $\mathrm{S}=\mathrm{I}$ in Traditional economics based on market price mechanism Can not play a role.

\subsubsection{Social Significance}

The humane expenditure of income has the function fulfilling social agent the needs of the second and third level, has broad social significance:

1) To advance the optimization of resources. In a high living level, social economy displays economic demand, the supplier fulfills social agent the needs of the second and third level in method of multistation, we think that it has the demand of humane value. The significance of humane value experienced subjectively by social agent is adjusted by market, so, enterprises which can provide the demand of goods' social use value can fulfill the demand of social agent's high level, and can promote preferably the realization of the value of goods, and advances the optimization of resources.

2) Promote the growth of enterprise value, social agent can get fill from the significance of humane value. So, which can prompt enterprise the production of human values, providing the significance of goods' social use value to meet Value model of social groups. When the product can bring social agent the fill of the significance of humane value, the social groups will express their concern and interest, and form the formation of value orientation after several payment and enjoyment. Enterprises with successful model of culture have the loyalty of main part of comprehensive social consumption, and enterprise gets more the social groups with value model and the potential of social cognition more, and more terms of value growth and aggregation of capital.

3) The level of social welfare improvement. As above shown, with the innovation of humane value of enterprise, every innovation can bring social agent higher utility fulfill of social use value, the whole society gets the growth of social welfare. Expressed as: U (area P1OqnA) > U (area P1Opn) and so on, if we expand it to the area of all social agent, the fulfill of all social agent can be used to illustrate the level of social welfare. Reaching the maximum $\mathrm{U}$ (area P1OpnE) expression: U (area P1OpnE) > U (area P1Opn).

\section{Conclusion}

Through the above theoretical analysis and empirical analysis, we make the following conclusion that: with the increasing of income, the phenomenon of markets failure is serious more and more, the same to the reality of market not clearing resources. Spiritual expenditure part of social agent breaks away from the adjustment of price in market in accelerated form. This is the current foundation that enterprise stimulates the payment behavior of social agent through humane value activities.

\section{REFERENCES}

[1] B. Zhao, "Outline of Human Values: The Principle of Value Running and the Mechanism of the Growth of Enterprise Value," Liaoning People's Publishing House, Shenyang, 2005.

[2] F. Sun, "The Quantitative Study of Consumer Behavior-Case Study of Chinese Urban Residents," Shanghai Sanlian Publishing House, Shanghai, 2002.

[3] J. Qian, "Labor Theory of Value," Social Science Literature Publishing Ltd., Shanghai, 2007.

[4] A. Menger, "Principles of National Economy," Shanghai People's Publishing House, Shanghai, 1995.

[5] W. S. Jevons, "Principles of Political Economy," Shanghai People's Publishing House, Shanghai, 1995.

[6] P. Drucker, "Innovation and Entrepreneurship," Shanghai People's Publishing House, Shanghai, 2002.

[7] W. Wang and F. Lv, "Network Assessment and Market Value," Economic Science Press, Beijing, 2000.

[8] J. M. Keynes, "The General Theory of Employment, Interest, and Money," Commercial Press, Shanghai, 1997. 